УДК 902.01

https://doi.org/10.24852/2587-6112.2020.6.248.252

\title{
УНИКАЛЬНАЯ НАХОДКА КИНЖАЛА ИЗ БОЛГАРА
}

\author{
(C) 2020 г. Р.P. Валиев
}

В публикации рассматривается уникальный для региона железный кинжал - баселард, происходящий с раскопа CLIII на территории Болгарского городища. Он представляет собой обоюдоострый клинок ромбовидного сечения с двумя долами, сходящимися к центру. Находка происходит с верхних горизонтов позднего золотоордынского слоя, датируемого концом XIV - первой половиной XV вв. Подобные кинжалы не типичны для памятников региона, и они не известны с территории Волжской Булгарии и Золотой Орды. Однако аналогичные находки кинжалов были обнаружены в Англии и северной Германии. Данный тип клинка был широко распространен в Центральной и Западной Европе в XIV-XV вв., появление которого традиционно связывают со швейцарским городом Базелем. Кинжал является импортом, и его появление в средневековом городе Болгаре, скорее всего, связано с европейскими торговцами.

Ключевые слова: археология, Поволжье, Болгарское городище, средневековье, золотоордынский период, кинжал, баселард.

\section{UNIQUE DAGGER FOUND IN BOLGAR}

\section{R.R. Valiev}

The publication concerns an iron dagger unique for the region in question - a baselard originating from excavation CLIII in the territory of Bolgar fortified settlement. It is a double-edged diamond-shaped blade with two lobes converging towards the center. The find was discovered in the upper horizons of the late Golden Horde layer dated the end of 14th - the first half of 15th centuries. Such daggers are not typical for the monuments of the region, and have not been discovered in the territory of Volga Bolgaria or the Golden Horde. However, similar daggers have been found in England and northern Germany. This type of blade was widely spread in Central and Western Europe in the 14th - 15th centuries, the appearance of which has been traditionally associated with the Swiss town of Basel. The dagger is an imported item, and its appearance in the medieval city of Bolgar is most likely associated with European traders.

Keywords: archaeology, Volga region, Bolgar fortified settlement, Middle Ages, Golden Horde period, dagger, baselard.

В 2010 г. во время охранных исследований Болгарского городища на раскопе CLIII обнаружена уникальная находка кинжала. Раскоп CLIII площадью 338 кв. м разбит на месте предстоящего строительства объектов инфраструктуры речного вокзала с функцией музея в северо-западной части памятника на краю коренной террасы левого берега р. Волги (Археологические исследования 2010 г. ..., 2011, с. 14-19).

В ходе исследований на раскопе CLIII были зафиксированы напластования современности и периода русского села, золотоордынского времени и домонгольского периода. Слой золотоордынского периода Болгара разделяется на два горизонта: верхний - позднезолотоордынский (30-40 гг. XIV в. - 30 гг. XV в.) и нижний - раннезолотоордынский (середина XIII - первая треть XIV вв.). IV поздний слой наиболее мощный (10-45 см) и более насыщен археологическими артефактами. Слой хорошо датируется медными пулами и одним серебряным дирхемом, где из 15 монет 10 относятся к 30-40 гг. и 60 гг. XIV в., осталь-

ные неопределимые или переотложенные к середине XIII - началу XIV вв. C IV поздним слоем соотносятся 32 объекта хозяйственнобытового и производственного назначения (Валиев, Бадеев, 2018, с. 137-138).

Из позднеордынского слоя происходили крицы, представленные как скоплениями мелких непрокованных, так и рублеными товарными крицами. В основном они концентрируются в западной и северо-восточной части раскопа, где располагались объекты усадьбы, датирующейся концом XIII - 40 гг. XIV в. Объекты данной усадьбы ко второй половине XIV вв. были засыпаны. С верхних горизонтов засыпки, датируемых концом $\mathrm{XIV}$ - первой половиной XV вв., происходит железный кинжал.

Он представляет собой обоюдоострый клинок ромбовидного сечения с двумя долами, сходящимися к центру. Вдоль центра лезвия проходила чётко выраженная грань, т. е. выпуклость (рис. 1: 1). На момент извлечения из земли, несмотря на плохую сохранность, кинжал был целым, позже облома- 
но острие. Общий вес - 300 г. Общая длина кинжала составляла 34 см, длина лезвия 23,5 см, длина эфеса - 10,5 cм, длина черенка $-8,5$ см. Клинок треугольной или конической формы, симметрично сужается от перекрестия к острию, ширина у перекрестия составляет 3,5 см, ширина - 1,7 см.

Перекрестие или гарда оформлена в виде наклонных от рукояти плечиков, и, судя по остаткам органики, имела деревянные накладки. Сохранившаяся ширина перекрестия -4 см.

Рукоять состояла из железного черенка толщиной $0,8-0,9$ см и шириной $1,5 \mathrm{~cm}$. На него с двух сторон накладывались тонкие медные пластины длиной 7,5 см, концы которых вырезаны полукругом и загнуты наружу на 0,5 см. На пластины накладывались деревянные детали - щёчки, которые сохранились в виде древесного тлена. Получившаяся конструкция рукояти в сечении имела размеры 2,2×1,5 см и длину 6,5 см. Она переходила в навершие (головку), оформленную в виде «Т»-образной петли. На головку также с двух сторон были наложены деревянные щёчки, сохранившиеся в виде древесного тлена. Вся конструкция эфеса скреплялась сквозными бронзовыми трубочками, длиной 1,8 см и диаметром 0,2 см: на перекрестии и навершии их по 2, на собственно рукояти -4 .

На территории Волжской Булгарии и Золотой Орды подобные кинжалы не обнаружены. Все известные находки кинжалов с территории Волжской Булгарии являются с однолезвийными или обоюдоострыми линзовидными в сечении клинками. Лезвие первой группы неширокое (до 1,7 см), длина достигает 29 см, у второй группы лезвие клиновидное (шириной до 6 см), длина - более 20 см (Белорыбкин, 1990, рис. 89: 1; Белорыбкин и др., 2020 , с. 37 ; Измайлов, 1997 , с. 56 , рис. 28,29$)$. Отсутствие отверстий на черенках свидетельствует о том, что их рукояти были втульчатыми, т. е. не скреплялись заклепками.

Кинжалы или короткие мечи с территории Золотой Орды, в том числе с подбором аналогий от Западной Европы до Восточного Казахстана, рассмотрены в коллективной статье, посвященной уникальной находке кинжала из средневекового могильника в Краснодарском крае. Клинки с территории Золотой Орды имеют обоюдоострое прямое или вытянуто-треугольное лезвие с ромбовидным или линзовидным сечением. Их длина составляет от 39 см до 55 см, хотя отдельные аналогичные клинки на Ближнем Востоке и Западной Европе достигают до 61 см и 63 см соответственно (Кулешов, Ничепорук, 2012, с. 182-198).

Кроме того, два обоюдоострых кинжала происходят с Болгарского городища. Один из них длиной до 39 см с ромбовидным сечением найден в слое XIV в. Второй кинжал клиновидный формы с линзовидным сечением происходит из смешанной коллекции (Савченкова, 1996, с. 69, рис. 32: 12-13). Как и у других кинжалов с территории Золотой Орды, на черенках данных клинков нет следов соединения деталей рукояти с помощью заклепок.

Рассматриваемый кинжал с раскопа CLIII относится к типу баселард (англ. baselard иногда читается как басселард, басселярд, базелард, базельяр) - тип кинжала и короткого меча, распространенного в Европе с конца XIII в. Название кинжала по основной и утвердившейся версии происходит от города Базеля в Швейцарии. Баселард был самым распространенным типом кинжала в Западной и Центральной Европе в XIV-XV вв., как в рыцарской среде, так и среди торговцев и фригольдеров. Если в XV в. рыцари перестают носить баселард, то горожане и пешие солдаты продолжают пользоваться им, пока к концу столетия он не выходит из употребления. К этому времени он имел крупную гарду и состоял из перекрестия и упора со стороны головки, так что эфес выглядел как римская цифра «I». Басселард имел двустороннюю заточку клинка, лезвия равномерно сужались к острию, рукоять изготовлялась из двух склёпанных вместе щитков из рога, дерева или слоновой кости (Асмолов, 1993, с. 178-179; Жарков, 2005, с. 49-51; Попенко, 1992, с. 214, рис. 18; Уиланд, 1998, с. 80; Laking, 1920, p. $8)$.

Детальные изображения и упоминания баселардов присутствуют во многих средневековых европейских источниках, будь то барельеф, рисунок, торговый и судебный документ, поэзия или фольклор. Благодаря этим данным можно проследить развитие и трансформацию данного типа кинжала. Первое изображение баселарда как короткого меча встречается на фреске 1288-1292 гг. на дворце заседания (Палаццо Комунале) в г. Сан-Джиминьяно в Италии, а первое письменное упоминание содержится во французских документах Дуэ, датируемых около 1300 г. К середине XIV в. баселард начинает отмечаться на англо-саксонских территориях. Баселар- 
ды в основном имеют длину, соответствующую трём размерам: около 35 см, 70 см и 100 см. Данные размеры приблизительно соответствовали распространённым в средневековой Европе единицам длины - футу (30-35 см) и «браччо» (итальянский локоть, 65-70 см) (Meier, 1998).

Кинжал из Болгара соответствует короткому варианту баселарда, полные аналогии которому происходят из северной Германии и Лондона. Первый датируется началом XV в., последний - концом XIV в. (Laking, 1920, p. 11, fig. 750, 751). Схожие баселарды, отличающиеся формами перекрестия и навершия, а также отсутствием дол были обнаружены в Германии. Один из них отнесён к началу $\mathrm{XV}$ в., второй имеет более точную датировку - около 1420 г. (Dufty, 1974, p. 34, pl. 95a; Laking, 1920, p. 11, fig. 748, 752; Thompson, 1996, pp. 52-55). Метрические параметры первого кинжала: длина лезвия 36,5 см, общая длина 45 см, общий вес 397 г (рис. 1: 3). К сожалению, для остальных вышеупомянутых баселардов не удалось найти характеристику параметров (рис. 1:2).
Подобные баселарды европейцы носили справа подвешенным к поясу, о чем свидетельствует рельефное изображении Иоганна фон Хольцхаузена и его жены Гуды на гробнице во Франкфуртском соборе. На этой плите Хольцхаузен опоясан с правой стороны кинжалом с треугольным клинком и рукоятью значительной длины (Laking, 1920, p. 11, fig. 749; Frankfurt Am Main-St Bartholomaeus...).

Таким образом, данный баселард из Болгара является уникальной находкой на обширной территории Золотой Орды. Отсутствие аналогичных кинжалов и техники изготовления подобных клинков и крепления с помощью сквозных бронзовых трубочек и, наоборот, наличие полных аналогий в Западной и Центральной Европе исключают изготовление данного кинжала на месте. Он является импортом, и его появление в средневековом городе Болгаре, скорее всего, связано с европейскими торговцами, носившими его как оружие самозащиты. Подобные уникальные находки еще раз подтверждают значимость Болгара как торгового и административного центра в Восточной Европе.

\section{ЛИТЕРАТУРА}

Археологические исследования 2010 г.: Болгар и Свияжск / Авт.-сост. Р.Р. Валиев, А.Г Ситдиков., 3.Г. Шакиров. Казань: Институт истории им. Ш.Марджани АН РТ, 2011. 40 с.

Асмолов К.В. История холодного оружия. Часть 1. М.: Оздоровительный и научно-информационный центр «Здоровье народа», 1993. 263 с.

Белорыбкин Г.Н. Новые открытия на Юловском городище // Поиски и находки. Кн. 2. Из записных книжек краеведов. Саратов: Приволжское кн. изд-во (Пензенское отделение), 1990. С. 3-9.

Белорыбкин Г.Н., Гусынин В.А., Измайлов И.Л. Вооружение населения Юго-Западной Булгарии (X-XIII века) / Археология Евразийских степей. 2020. № 1. 354c.

Валиев Р.Р., Бадеев Д.Ю. Результаты археологических исследований на Болгарском городище в 2010 г. (раскоп CLIII) // Археология Евразийских степей. 2018. №5. С. 137-143.

Жарков С.В. История создания рыцарских орденов и каталог холодного оружия, снаряжения рыцарей средневековой Европы. Брест: Академия, 2005. 108 с.

Измайлов И.Л. Вооружение и военное дело населения Волжской Булгарии X - начала XIII в. КазаньМагадан: СВНЦ ДВО РАН, 1997. 212 с.

Кулешов Ю.А., Ничепорук А.А. Находка уникального кинжала из могильника Жукова (к вопросу о «гражданском» оружии в Золотой Орде) // Военное дело Улуса Джучи и его наследников / Отв. ред. А.К. Кушкумбаев. Астана: Фолиант, 2012. С. 182-198.

Попенко В.Н. Холодное оружие Востока и Запада. М.: Горбунок, 1992. 213 с.

Савченкова Л.Л. Черный металл Болгара. Типология // Город Болгар: Ремесло металлургов, кузнецов, литейщиков / Отв. ред. Г.А. Федоров-Давыдов. Казань: ИЯЛИ им. Г. Ибрагимова АН Татарстана, 1996. С. 5-88.

Уиланд Джеральд. Мечи, шпаги и сабли. Настольная книга коллекционера / пер. с англ. яз. С. Кулланда. М.: Издательство «Тривиум», 1998. 128 с.

Arthur Richard Dufty. European Swords and Daggers in the Tower of London. London: H.M. Stationery Office, 1974. $157 \mathrm{p}$.

Guy Francis Laking. A Record of European Armour and Arms. L: G. Bell and Sons, Ltd, 1920. Vol. III. 
Jürg A. Meier. Sammlung Carl Beck Sursee. Schweizerische Gesellschaft für Historische Waffen und Rüstungskunde, Luzerne, 1998. 114 p.

Frankfurt Am Main-St Bartholomaeus-Grabmal des Johann von Holzhausen und seiner Frau Gudula-20080208.jpg. URL: https: // commons.wikimedia.org / wiki / File: Frankfurt Am Main-St Bartholomaeus-Grabmal des Johann von Holzhausen und seiner Frau Gudula-20080208.jpg. Дата обращения 08.12.2020

Thompson A.L. Medieval Daggers // Military Illustrated. 1996. No. 102. P. 52-55.

\section{Информация об авторе:}

Валиев Ренат Рафаилович, кандидат исторических наук, старший научный сотрудник, Институт археологии им. А.Х. Халикова АН РТ (г. Казань, Россия); vrr80@yandex.ru

\section{REFERENCES}

Valiev, R. R., Sitdikov, A. G., Shakirov Z. G. (comp.). 2011. Arkheologicheskie issledovaniia 2010 g.: Bolgar i Sviiazhsk (Archaeological Studies in 2010: Bolgar and Sviyazhsk). Kazan: Institute of History named after Shigabuddin Mardzhani, Tatarstan Academy of Sciences (in Russian).

Asmololov, K. V. 1993. Istoriia kholodnogo oruzhiia (History of Melee Weapons) 1. Moscow: "Zdorov'e naroda" Publ. (in Russian).

Belorybkin, G. N. 1990. In Poiski i nakhodki. 2. Iz zapisnykh knizhek kraevedov (Searches and Finds. Book 2. From the Notebooks of Local Historians). Saratov: Privolzhskoe kn. izd-vo (Penzenskoe otdelenie) Publ., 3-9 (in Russian).

Belorybkin, G. N., Gusynin, V. A., Izmailov, I. L. 2020. Vooruzhenie naseleniia yugo-zapadnoi Bulgarii (X - XIII veka) Armament of the Population of South-Western Bolgaria (10th - mid-13th centuries). Arkheologiia Evraziiskikh stepei (Archaeology of Eurasian Steppes) 1 (in Russian).

Valiev, R. R. 2018. In Arkheologiia Evraziiskikh stepei (Archaeology of Eurasian Steppes) 5. 211-226 (in Russian).

Zharkov, S. V. 2005. Istoriia sozdaniia rytsarskikh ordenov $i$ katalog kholodnogo oruzhiia, snariazheniia rutsarei srednevekovoi Evropu (The History of the Creation of Knightly Orders and the Catalog of Melee Weapons equipment of Medieval European Knights). Brest: "Akademiia” Publ. (in Russian).

Izmaylov, I. L. 1997. Vooruzhenie $i$ voennoe delo naseleniya Volzhskoy Bulgarii X - nachala XIII v. (Armament and Warfare of the population of Volga Bulgaria 10th-beginning of 13th century) Kazan-Magadan: North-East Scientific Center, Russia Academy of Sciences Far East Branch (in Russian).

Kuleshov, Yu. A., Nicheporuk, A. A. 2012. In Kushkumbaev, A. K. (ed.). Voennoe delo Ulusa Dzhuchi i ego naslednikov (Military Affairs of Ulus of Jochi and its Heirs). Astana: "Foliant" Publ., 182-198 (in Russian).

Popenko, V. N. 1992. Kholodnoe oruzhie Vostoka I Zapada (Melee Weapons of the East and West). Moscow: "Gorbunok" Publ. (in Russian).

Savchenkova, L. L. 1996. In Fedorov-Davydov, G. A. (ed.). Gorod Bolgar. Remeslo metallurgov, kuznetsov, liteishchikov (Town of Bolgar. Craft of Metallurgists, Smiths, Founders). Kazan: Institute for Language, Literature and History Institute named after G. Ibragimov, Academy of Sciences of Tatarstan, 5-88 (in Russian).

Jerald Weland. 1998. Mechi, shpagi i sable. Nastol'naia kniga koolektsionera (A collector's guide to swords, daggers and gutlasses). Trans. Kulland, S. Moscow: "Triumf” Publ.

Dufty, Arthur Richard. 1974. European Swords and Daggers in the Tower of London. London: H.M. Stationery Office (in English).

Guy Francis Laking.1920. A Record of European Armour and Arms. L: G. Bell and Sons, Ltd, 1920. Vol. III (in English).

Jürg A. Meier. Sammlung Carl Beck Sursee. Schweizerische Gesellschaft für Historische Waffen und Rüstungskunde, Luzerne, 1998. 114 p.

Frankfurt Am Main-St Bartholomaeus-Grabmal des Johann von Holzhausen und seiner Frau Gudula-20080208.jpg. URL: https: // commons.wikimedia.org / wiki / File: Frankfurt Am Main-St Bartholomaeus-Grabmal des Johann von Holzhausen und seiner Frau Gudula-20080208.jpg. Дата обращения 08.12.2020

Thompson A.L. 1996. In Military Illustrated 102, 52-55 (in English). 


\section{About the Author:}

Valiev Renat R. Candidate of Historical Sciences, Institute of Archaeology named after A. Kh. Khalikov, Academy of Sciences of the Republic of Tatarstan. Butlerov Str., 30, Kazan, 420012, the Republic of Tatarstan, Russian Federation; vrr80@yandex.ru

Статья поступила в журнал 01.08.2020 г. Статья принята к публикации 01.09.2020 г.
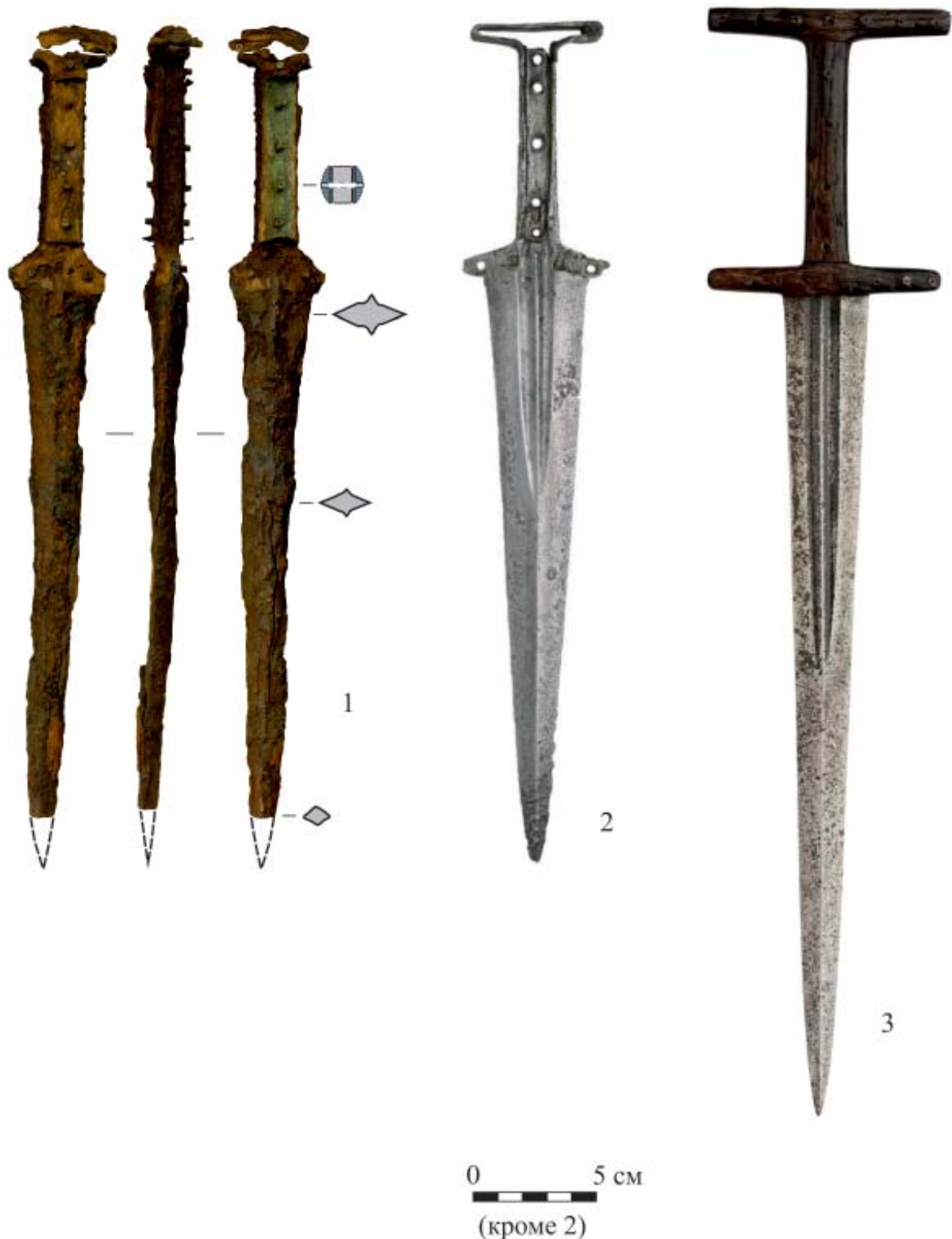

Рис. 1. Находки баселардов: 1 - Болгар, конец XIV-первая половина XV вв.; 2 - Лондон, конец XIV в.; 3 - Северная Германия, XV в.

Fig. 1. Discovered baselards: 1 - Bolgar, late 14th - first half of 15th cc.; 2 - London,late 14th c.; 3 - Northern Germany, 15 th c. 